\title{
Effect of Desflurane versus Sevoflurane in Pediatric Anesthesia: A Meta-Analysis
}

Jiaxuan He MM, Yong Zhang* PhD, Rongliang Xue MM, Jianrui Lv MM, Xiaoying Ding MM, Zhenni Zhang MM

Department of Anesthesiology, the Second Affiliated Hospital of Xi'anJiaotong University, No. 157, West 5th Road, Xi'an, Shaanxi Province, China

Received, March 20, 2015; Accepted, May 22, 2015; Published, May 25, 2015.

\begin{abstract}
Purpose: To compare the effect of desflurane versus sevoflurane in pediatric anesthesia by conducting meta-analysis. Methods: Studies were searched from PubMed, Medline, Springer, Elsevier Science Direct, Cochrane Library and Google Scholar up to July 2014. Weighted mean difference (WMD) or risk ratio (RR) and 95\% confidence intervals (CIs) were considered as effect sizes. Heterogeneity across studies was assessed by Cochran Q test and $I^{2}$ statistic. The random effects model was performed in the meta-analysis when heterogeneity was observed, or the fixed effect model was used. Review Manager 5.1 software was applied for the meta-analysis. Results: A total of 11 studies (13 comparisons) involving 1,273 objects were included in this meta-analysis. No heterogeneity was observed between studies for any comparison but for postoperative extubation time. The results showed significant differences between desflurane and sevoflurane groups for postoperative extubation time $(\mathrm{WMD}=-3.87,95 \% \mathrm{CI}=-6.14$ to -1.60 , $P<0.01$ ), eye opening time ( $\mathrm{WMD}=-1.11,95 \% \mathrm{CI}=-1.49$ to $-0.72, P<0.01$ ), awakening time $(\mathrm{WMD}=$ $-4.27,95 \% \mathrm{CI}=-5.28$ to $-3.26, P<0.01)$ and agitation $(\mathrm{RR}=1.44,95 \% \mathrm{CI}=1.05$ to $1.96, P=0.02)$. No significant differences $(P>0.05)$ were detected for discharge from the recovery room, oculocardiac reflex, nausea and vomiting and severe pain. Conclusions: Desflurane may have less adverse effects than sevoflurane when used in pediatric anesthesia with significantly shorter postoperative extubation time, eye opening time and awakening time as well as slighter agitation.
\end{abstract}

This article is open to POST-PUBLICATION REVIEW. Registered readers (see "For Readers") may comment by clicking on ABSTRACT on the issue's contents page.

\section{INTRODUCTION}

Anesthesia is needed for the pediatric patient who is under operation or treatment, theoretically ensuring ideal outcomes $(1,2)$. Anesthesia therapies have been the mainstay of pain treatment in pediatric care (3). Moreover, regional anesthesia is increasingly applied in pediatric practice (4). For instance, spinal anesthesia in pediatrics has been used in multiple procedures since the late nineteenth century (5). Nowadays, the anesthesia in pediatric daily practice is frequently performed by inhalational anesthetic agents (6).

Desflurane, as an inhalational anesthetic agent, has the advantages of rapid onset and offset of action for general anesthesia especially in pediatric patients (7). Sevoflurane, another inhalational anesthetic agent, has been widely used in induction and maintenance of anesthesia because of its rapid uptake and elimination (8). Both desflurane and sevoflurane yield rapid emergence and recovery from general anesthesia (9). Several previous studies have found that desflurane is beneficial in comparison to sevoflurane in pediatric anesthesia
(9-13). However, Oh et al. (14) has found no difference between desflurane and sevoflurane anesthesia based on the incidence of the oculocardiac reflex (OCR). Furthermore, another study has declared that desflurane brought more complications than sevoflurane in pediatric anesthesia, such as coughing episodes (15). Thus, whether the effect of desflurane in pediatric anesthesia is superior to sevoflurane remains controversial.

In the present study, a systematic review and meta-analysis was conducted to identify the relevant studies, in which desflurane and sevoflurane were used in pediatric patients. We analyzed postoperative extubation time, eye opening, awakening time, discharge from the recovery room, OCR, agitation, nausea and vomiting, and severe pain in pediatric anesthesia with desflurane and sevoflurane. Our findings could provide an integrative comparison of effect

Corresponding Author: Yong Zhang, Department of Anesthesiology, the Second Affiliated Hospital of Xi'anJiaotongUniversity, No.157, West5thRoad, Xi'an, Shaanxi Province, China. Email: yongzhahzh@163.com 
between desflurane and sevoflurane in pediatric anesthesia.

\section{METHODS}

Data sources and search strategy

The relevant studies were retrieved from several public databases, including PubMed, Medline, Springer, Elsevier Science Direct, Cochrane Library and Google Scholar up to July 2014. The key words used for searching were as follows: "desflurane", "sevoflurane", "pediatric anesthesia", "children", "study" and "trial". Six investigators independently retrieved the electronic databases. An independent PubMed and Medline retrieve was done by A and B with the same method. Meanwhile, a Springer and Elsevier Science Direct retrieve was done by $\mathrm{C}$ and $\mathrm{D}$, and a Cochrane Library and Google scholar retrieve was done by $\mathrm{E}$ and $\mathrm{F}$. Besides, the reference lists of the retrieved papers were manually checked for additional studies by $\mathrm{C}$ and $\mathrm{F}$ independently.

\section{Inclusion and exclusion criteria}

The inclusion criteria of studies mainly comprised: (1) the objects in the study were children in pediatric anesthesia; (2) the study was designed a randomized controlled trial (RCT); (3) comparison between desflurane and sevoflurane groups were provided; (4) the effect size of postoperative extubation time, eye opening time, awakening time, discharge from the reciveryroom was weighted mean difference (WMD), the effect size of OCR, agitation, nausea and vomiting, severe pain was risk ratio (RR).We excluded the studies when they were: (1) studies with description of sevoflurane or desflurane only; (2) reviews, reports, meetings or conference abstracts; (3) reduplicated studies or records.

\section{Data extraction and quality assessment}

Data items were extracted by two investigators (A and D) independently using the standard protocol. The data from the included studies contained study details (e.g., the first author's name, research year of study, publication year of study, design of study) and characteristics of objects (e.g., age, gender, location and sample size). The third investigator (E) reviewed their results. Disagreement was resolved by discussion among our research team or contacting with the original authors via e-mail.

The quality of the included studies was assessed according to the method of Jadad (16), , a 5 score system for evaluation. The Jadad scale was used with a maximum score of 5 . The study was considered as high quality when the score ranged from 3 to 5 and low quality if the score less than 3 .
Meta-analysis

WMD or RR and its $95 \%$ confidence interval $(95 \% \mathrm{CI})$ were estimated as the effect size to assess postoperative extubation time, eye opening, awakening time, discharge from the recovery room, OCR, agitation, nausea and vomiting, and severe pain. Heterogeneity across studies was analyzed by Cochran Q test and $I^{2}$ statistic. When the results indicated a significant heterogeneity $\left(I^{2}>50 \%, P<\right.$ 0.05 ), the random effects model was used for meta-analysis. Otherwise, the fixed effect model was performed.

The meta-analysis was performed using the software of Review Manager 5.1 (Cochrane Collaboration, http://ims.cochrane.org/revman). The $P$-value less than 0.05 was considered statistically significant.

\section{Evaluation of publication bias}

Publication bias of the included studies was evaluated using Egger's linear regression test (17).

\section{RESULTS}

\section{Results of study selection}

The study selection process is shown in Figure 1. Initially, there were 871 studies identified according to the search terms (PubMed: 265; Medline: 126; Springer: 151; Elsevier Science Direct: 107; Cochrane Library: 12; Google Scholar: 210). Then 85 potentially relevant studies were remained after removing duplicates or irrelevant studies. During the step of screening abstracts, 54 studies were excluded (23 were reviews; 31 were not RCT). Subsequently, 31 studies were left for full text reading, 20 of which were excluded (12 only reported desflurane data but not involved the comparison; 7 provided no available data; 1 was retracted by the journal). Ultimately, 11 studies $(10-15,18-22)$ were included in the meta-analysis.

\section{Characteristics of eligible studies}

The characteristics of included studies were presented in Table 1. The included studies were published between 1996 and 2014. A total of 1,273 children in pediatric anesthesia (desflurane group: 630; sevoflurane group: 643) were considered in the meta-analysis. The sample sizes in desflurane and sevoflurane groups varied from 20-124. The average age ranged from 2.0 to 10.7 years. All the studies were designed as RCTs. There were 13 comparisons in total, due to 2 comparisons in each study by Demirbilek et al. (21) and Choi et al. (22). As shown in Table 2, the Jadad score of 7 included studies were no less than 3 , representing high quality, and 5 studies were low-quality with the score of 2 . 


\section{1 potentially relevant studies identified and screened (PubMed: 265; Medline: 126; Springer: 151; Elsevier Science Direct: 107; Cochrane Library: 12; Google Scholar: 210)}

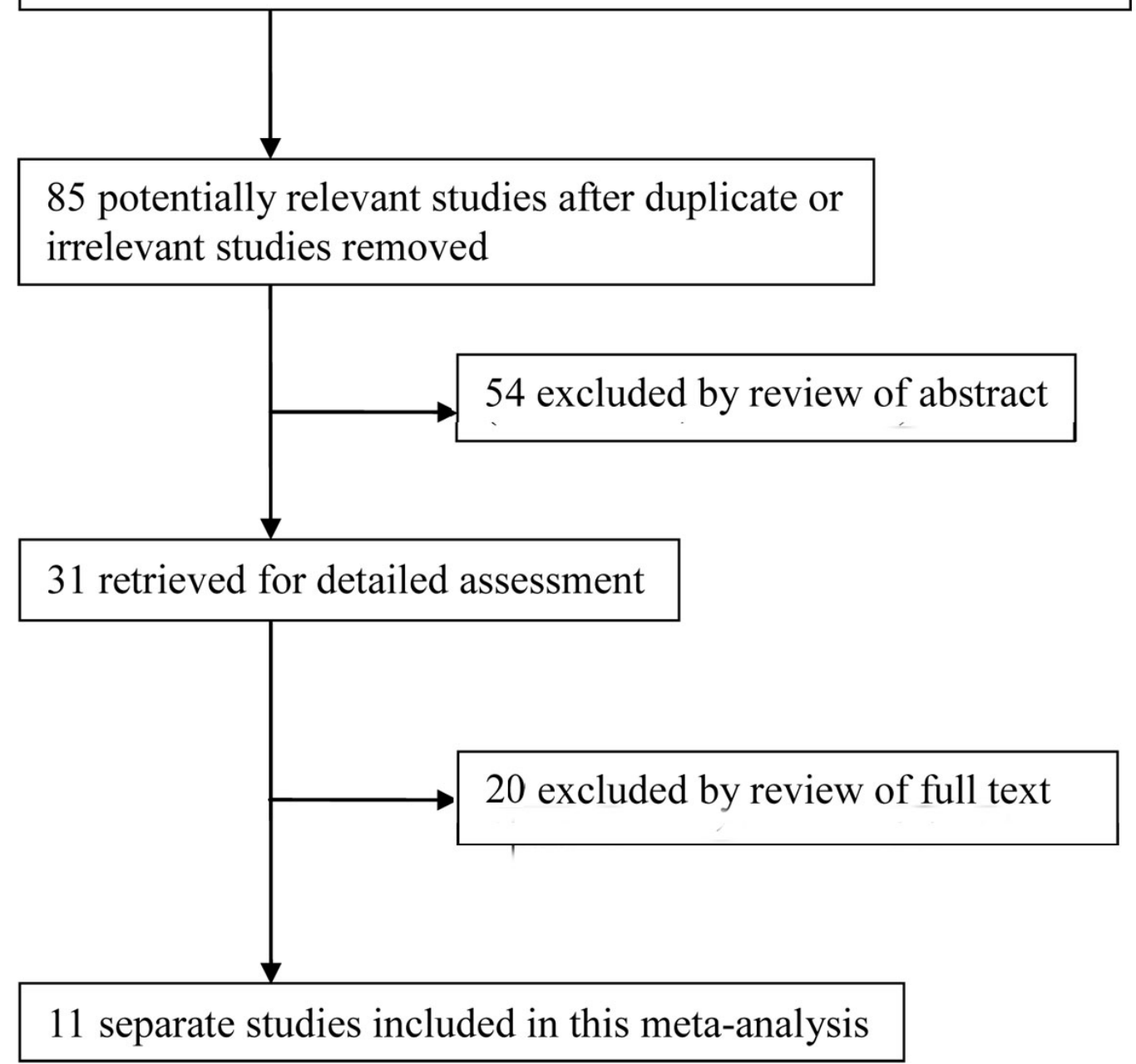

Figure 1. The flowchart of literature selection.

Overall effects of postoperative extubation time The summary of postoperative extubation time between desflurane and sevoflurane groups in this meta-analysis are shown in Table 3 . Three studies $(10,18,21)$ (5 comparisons) consisting of 298 children in pediatric anesthesia (desflurane group: 149; sevoflurane group: 149) were involved in the meta-analysis. The heterogeneity test showed a significant heterogeneity between the studies $\left(I^{2}=\right.$ $96 \%, P<0.01)$, so the random effects model was used to pool the data. The overall meta-analysis showed that there were significant differences $(\mathrm{WMD}=-3.87,95 \% \mathrm{CI}=-6.14$ to $-1.60, P<0.01)$ in patients between the two groups.

\section{Overall effects of eye opening time}

There were 3 studies $(10,11,15)$ consisting of 236 children in pediatric anesthesia (desflurane group: 118; sevoflurane group: 118) been analyzed in the meta-analysis. No heterogeneity across the studies was observed (Table $3, I^{2}=0 \%, P=0.84$ ), then we performed the fixed effect model. The overall results showed significant differences (Table 3, $\mathrm{WMD}=-1.11,95 \% \mathrm{CI}=-1.49$ to $-0.72, P<0.01)$ in patients between the two groups. 
Overall effects of awakening time

A total of 5 comparisons consisting of 271 objects in desflurane group and 272 objects in sevoflurane group were involved in 4 studies $(12,19-21)$. There were no heterogeneity existed (Table $3, I^{2}=27 \%, P$ $=0.24$ ), thus the comparison of awakening time between the two groups were evaluated with the fixed effect model. A statistical significance was found in patients between the two groups (Table 3, $\mathrm{WMD}=-4.27,95 \% \mathrm{CI}=-5.28$ to $-3.26, P<0.01)$.

Overall effects of discharge from the recovery room We analyzed 4 studies $(10,15,20,21)$ (5 comparisons), consisting of 154 cases in desflurane group and 154 in sevoflurane group. The fixed effect model was applied to evaluated the discharge from the recovery room due to no evidence of heterogeneity between the studies (Table $3, I^{2}=0 \%$, $P=0.78$ ). As shown in Table 3 , no significant differences were provided by the overall meta-analysis of the discharge from the recovery room $(\mathrm{WMD}=-0.91,95 \% \mathrm{CI}=-6.23$ to $4.41, P=$ $0.74)$.

\section{Overall effects of OCR}

Three comparisons in 2 included studies $(14,22)$ were available in our meta-analysis of OCR. There were 374 children in pediatric anesthesia, consisting of 181 in desflurane group and 193 in sevoflurane group. The analysis of OCR was presented in Table 3. After the heterogeneity test, no heterogeneity was obtained according to $I^{2}=0 \%$, $P=0.69$. The overall meta-analysis of OCR was gained by conducting the fixed effect model $(\mathrm{RR}=$ $1.03,95 \% \mathrm{CI}=0.75$ to $1.40, P>0.87$ ), showing that desflurane group has no significant differences in comparison to sevoflurane group.

\section{Overall effects of agitation}

Five separate studies $(10,15,18,20,21)$ (6 comparisons), consisting of 444 children in pediatric anesthesia (desflurane group: 222, sevoflurane group: 222) reported the agitation in the meta-analysis. As homogeneity across the studies was shown in Table 3 (I2 $=5 \%, \mathrm{P}=0.38$ ), the fixed effects model was chosen. Agitation were found to be significant different between desflurane and sevoflurane groups (Table 3, RR $=1.44$, $95 \% \mathrm{CI}=1.05$ to $1.96, P=0.02$ ).

\section{Overall effects of nausea and vomiting}

There were 6 separate studies $(10,11,13,15,20$, 21 ), actually 7 comparisons, analyzed in the meta-analysis with 238 objects in desflurane group and 238 objects in sevoflurane group. The results of heterogeneity test has no statistical significance $\left(I^{2}\right.$ $=0 \%, P=0.49$ ), as a result, the fixed effects model was used to conduct the meta-analysis of nausea and vomiting. The overall results were: $\mathrm{RR}=1.12$, $95 \% \mathrm{CI}=0.78$ to $1.62, P=0.54$. This suggested that there were significant differences in nausea and vomiting between the two groups.

\section{Overall effects of severe pain}

Severe pain was mentioned in 2 included studies $(10,21)$ (3 comparisons). Totally, 110 cases in desflurane group and 110 cases in sevoflurane group were involved in the meta-analysis. No heterogeneity between the studies was gained, basing on $I^{2}=0 \%, P=0.73$ (Table 3). Following the preformation of the fixed effects model, the overall meta-analysis of severe pain was shown with a significant difference (Table $3, R R=0.95$, $95 \% \mathrm{CI}=0.68$ to $1.33, P=0.78$ ) between the two groups.

\section{Evaluation of publication bias analysis}

The Egger's linear regression test in Table 3 showed that there were no publication bias in the subgroups $(P>0.05)$ except postoperative extubation time $(P<0.01)$ and awakening time $(P$ $=0.03$ ).

\section{DISCUSSION}

Many studies have reported the effect with desflurane versus sevoflurane in pediatric anesthesia $(12-15,22)$. However, they have shown mixed results due to small sample sizes or low statistical power. In the present study, 11 studies, consisting of 1,273 children in pediatric anesthesia (desflurane group: 630; sevoflurane group: 643) were involved in the meta-analysis. In general, our meta-analysis suggests that desflurane used in pediatric anesthesia may have less adverse effects than sevoflurane.

Our study suggested significant differences on postoperative extubation time, eye opening time, awakening time and agitation between desflurane and sevoflurane groups. Firstly, postoperative extubation time, eye opening time and awakening time in desflurane group were significant earlier than sevoflurane group. Similarly, previous meta-analysis of postoperative recovery after anesthesia with sevoflurane or desflurane has suggested that patients receiving desflurane recover quicker in the operating room than patients receiving sevoflurane, and they were extubated sooner (23). Secondly, the meta-analysis of agitation indicated that children recovered from 
pediatric anesthesia in sevoflurane group showed obvious agitation compared to desflurane group. Emergence agitation has been documented as a common adverse effect of anesthesia in children (24). Therefore, desflurane may have less adverse effects than sevoflurane with shorter postoperative extubation time, eye opening time and awakening time, and slighter agitation.

On the contrary, there were no significant differences for discharge from the recovery room, OCR, nausea and vomiting, and severe pain between the two groups. By reviewing the data from the included studies, we found that the population were distributed into various countries, such as USA, Turkey, Korea, Egypt etc. This may affect our results of analysis. Another factor may be the different average age of objects in each comparison. Although the quality of most of the included studies (7/12) was in a high level, the method of blinding in all of studies was not described and may be inappropriate. Five studies were low-quality due to the absence of description of the randomization method and double-blind. Thus, we inferred that the quality of the included studies may be the third cause that influenced the evaluation of the effect of desflurane and sevoflurane.

Some limitations of this study should be discussed. Firstly, significant heterogeneity for postoperative extubation time was detected in the current meta-analysis, which may distort the results. The degree of heterogeneity is one of the major concerns in meta-analysis for the validity (25), as heterogeneous data are liable to mislead the results. In our meta-analysis, heterogeneity may be caused by the different races of the objects and sample sizes. Secondly, the sample sizes of some recruited studies were small. To minimize the likelihood of bias, we developed a detailed protocol before initiating the study, performing a meticulous search for published studies and using explicit methods for study selection, data extraction and data analysis.

In conclusion, desflurane may has less adverse effects on children than sevoflurane due to shorter postoperative extubation time, eye opening time and awakening time after pediatric anesthesia as well as slighter agitation. However, further study is needed to verify our findings with more high-quality studies and larger sample sizes.

\section{CONFLICT OF INTEREST STATEMENT}

The authors have declared that no competing interests exist.

\section{REFERENCES}

1. Eshghi A, Samani M J, Najafi N F, Hajiahmadi M. Evaluation of efficacy of restorative dental treatment provided under general anesthesia at hospitalized pediatric dental patients of Isfahan. Dental research journal,9:478-482, 2012.

2. Tate A R, Ng M W, Needleman H L, Acs G. Failure rates of restorative procedures following dental rehabilitation under general anesthesia. Pediatric dentistry,24:69-69, 2002.

3. Rork J F, Berde C B, Goldstein R D. Regional anesthesia approaches to pain management in pediatric palliative care: a review of current knowledge. Journal of pain and symptom management, 46:859-873, 2013.

4. Ecoffey C. Safety in pediatric regional anesthesia. Paediatric anaesthesia,22:25-30, 2012.

5. Lopez T, Sanchez F J, Garzon J C, Muriel C. Spinal anesthesia in pediatric patients. Minerva anestesiologica,78:78-87, 2012.

6. Lerman J. Inhalational anesthetics. Pediatric Anesthesia, 14:380-383, 2004.

7. Kim E J, Shin S W, Kim T K, Yoon J U, Byeon G J, Kim H J. The median effective effect-site concentration of remifentanil for minimizing the cardiovascular changes to endotracheal intubation during desflurane anesthesia in pediatric patients. Korean journal of anesthesiology,63:314-320, 2012.

8. Cravero J, Surgenor S, Whalen K. Emergence agitation in paediatric patients after sevoflurane anaesthesia and no surgery: a comparison with halothane. Pediatric Anesthesia, 10:419-424, 2000.

9. Cohen I T, Finkel J C, Hannallah R S, Hummer K A, Patel K M. The effect of fentanyl on the emergence characteristics after desflurane or sevoflurane anesthesia in children. Anesthesia \& Analgesia,94:1178-1181, 2002.

10. Cohen I T, Finkel J C, Hannallah R S, Hummer K A, Patel K M. The effect of fentanyl on the emergence characteristics after desflurane or sevoflurane anesthesia in children. Anesthesia and analgesia,94:1178-1181, table of contents, 2002.

11. Sethi S, Ghai B, Ram J, Wig J. Postoperative emergence delirium in pediatric patients undergoing cataract surgery--a comparison of desflurane and sevoflurane. Paediatric anaesthesia,23:1131-1137, 2013.

12. Locatelli B G, Ingelmo $\mathrm{P}$ M, Emre S, Meroni V, Minardi C, Frawley G, Benigni A, Di Marco S, Spotti A, Busi I, Sonzogni V. Emergence delirium in children: a comparison of sevoflurane and desflurane anesthesia using the Paediatric Anesthesia Emergence Delirium scale. Paediatric anaesthesia,23:301-308, 2013.

13. Isik Y, Goksu S, Kocoglu H, Oner U. Low flow desflurane and sevoflurane anaesthesia in children. European journal of anaesthesiology,23:60-64, 2006.

14. Oh A Y, Yun M J, Kim H J, Kim H S. Comparison 
of desflurane with sevoflurane for the incidence of oculocardiac reflex in children undergoing strabismus surgery. British journal of anaesthesia,99:262-265, 2007.

15. Valley R D, Freid E B, Bailey A G, Kopp V J, Georges L S, Fletcher J, Keifer A. Tracheal extubation of deeply anesthetized pediatric patients: a comparison of desflurane and sevoflurane. Anesthesia and analgesia,96:1320-1324, table of contents, 2003.

16. Jadad A R, Moore R A, Carroll D, Jenkinson C, Reynolds D J M, Gavaghan D J, Mcquay H J. Assessing the quality of reports of randomized clinical trials: is blinding necessary? Controlled clinical trials, 17:1-12, 1996.

17. Egger M, Davey Smith G, Schneider M, Minder C. Bias in meta-analysis detected by a simple, graphical test. BMJ (Clinical research ed),315:629-634, 1997.

18. Ghoneim A A, Azer M S, Ghobrial H Z, El Beltagy M A. Comparative Study Between Isoflurane, Sevoflurane, and Desflurane in Neurosurgical Pediatric Patients Undergoing Craniotomy for Supratentorial Tumor Resection. Journal of neurosurgical anesthesiology, 2014.

19. Oofuvong M, Siripruekpong S, Naklongdee J, Hnookong R, Lakateb C. Comparison the incidence of emergence agitation between sevoflurane and desflurane after pediatric ambulatory urologic surgery. Journal of the Medical Association of Thailand; 96:1470-1475, 2013.
20. Welborn L G, Hannallah R S, Norden J M, Ruttimann U E, Callan C M. Comparison of emergence and recovery characteristics of sevoflurane, desflurane, and halothane in pediatric ambulatory patients. Anesthesia and analgesia,83:917-920, 1996.

21. Demirbilek S, Togal T, Cicek M, Aslan U, Sizanli E, Ersoy M O. Effects of fentanyl on the incidence of emergence agitation in children receiving desflurane or sevoflurane anaesthesia. European journal of anaesthesiology,21:538-542, 2004.

22. Choi S R, Park S W, Lee J H, Lee S C, Chung C J. Effect of different anesthetic agents on oculocardiac reflex in pediatric strabismus surgery. Journal of anesthesia,23:489-493, 2009.

23. Macario A, Dexter F, Lubarsky D. Meta-analysis of trials comparing postoperative recovery after anesthesia with sevoflurane or desflurane. American journal of health-system pharmacy,62:63-68, 2005.

24. Ibacache M E, Muñoz H R, Brandes V, Morales A L. Single-dose dexmedetomidine reduces agitation after sevoflurane anesthesia in children. Anesthesia \& Analgesia,98:60-63, 2004.

25. Moreno S G, Sutton A J, Thompson J R, Ades A E, Abrams K R, Cooper N J. A generalized weighting regression-derived meta-analysis estimator robust to small-study effects and heterogeneity. Statistics in medicine, 31:1407-1417, 2012. 
J Pharm Pharm Sci (www.cspsCanada.org) 18(2) 199 - 206, 2015

Table 1. Characteristics of included studies in the meta-analysis

\begin{tabular}{|c|c|c|c|c|c|c|c|}
\hline \multirow[b]{2}{*}{ Source } & \multirow[b]{2}{*}{ Country } & \multicolumn{3}{|c|}{ Desflurane group } & \multicolumn{3}{|c|}{ Sevoflurane group } \\
\hline & & $\begin{array}{l}\text { Sample } \\
\text { size }\end{array}$ & $\begin{array}{l}\text { Age, years } \\
(\text { mean } \pm \text { SD) }\end{array}$ & Intervention measure & $\begin{array}{l}\text { Sample } \\
\text { size }\end{array}$ & $\begin{array}{l}\text { Age, years } \\
(\text { mean } \pm \text { SD) }\end{array}$ & Intervention measure \\
\hline Welborn 1996 & USA & 20 & $2.0 \pm 1.4$ & Desflurane+Halothane & 20 & $3.0 \pm 1.8$ & Sevoflurane+Halothane \\
\hline Cohen 2002 & USA & 50 & $4.2 \pm 1.3$ & Desflurane & 50 & $3.9 \pm 1.4$ & Sevoflurane \\
\hline Valley 2003 & USA & 24 & $3.6 \pm 3.2$ & Desflurane & 24 & $3.0 \pm 2.9$ & Sevoflurane \\
\hline Demirbilek 2004a & Turkey & 30 & $5.2 \pm 1.4$ & Desflurane & 30 & $5.0 \pm 1.6$ & Sevoflurane \\
\hline Demirbilek 2004b & Turkey & 30 & $5.3 \pm 1.5$ & Desflurane+Fentanyl & 30 & $5.0 \pm 1.4$ & Sevoflurane + Fentanyl \\
\hline Isik 2006 & Turkey & 40 & $8.3 \pm 3.1$ & Desflurane & 40 & $8.8 \pm 3.1$ & Sevoflurane \\
\hline Oh 2007 & Korea & 114 & 7.1 & Desflurane & 123 & 6.9 & Sevoflurane \\
\hline Choi 2009a & Korea & 34 & $4.7 \pm 1.8$ & Desflurane+Ketamine & 35 & $4.9 \pm 2.1$ & Sevoflurane + Ketamine \\
\hline Choi 2009b & Korea & 33 & $5.3 \pm 1.8$ & Desflurane+Midazolam & 35 & $5.2 \pm 1.9$ & Sevoflurane+Midazolam \\
\hline Locatelli 2013 & Italy & 123 & $3.6 \pm 1.7$ & Desflurane & 124 & $3.3 \pm 1.5$ & Sevoflurane \\
\hline Oofuvong 2013 & Thailand & 68 & NA & Desflurane & 68 & NA & Sevoflurane \\
\hline Sethi 2013 & France & 44 & $2.7 \pm 1.5$ & Desflurane & 44 & $2.5 \pm 1.2$ & Sevoflurane \\
\hline Ghoneim 2014 & Egypt & 20 & $10.7 \pm 2.4$ & Desflurane & 20 & $9.9 \pm 2.4$ & Sevoflurane \\
\hline
\end{tabular}

Table 2. Jadad scoring items of each eligible study for meta-analysis

\begin{tabular}{lcccccc}
\hline \multicolumn{7}{l}{ Table 2. Jadad scoring items of each eligible study for meta-analysis } \\
\hline Study & Randomized? & $\begin{array}{c}\text { Appropriate } \\
\text { randomization? }\end{array}$ & $\begin{array}{c}\text { Double } \\
\text { blind? }\end{array}$ & $\begin{array}{c}\text { Blinding } \\
\text { described and } \\
\text { appropriate? }\end{array}$ & $\begin{array}{c}\text { Withdrawals } \\
\text { and dropouts } \\
\text { described? }\end{array}$ & $\begin{array}{c}\text { Jadad } \\
\text { score }\end{array}$ \\
\hline Welborn 1996 & Yes & Yes & Yes & NA & Yes & 4 \\
Cohen 2002 & Yes & NA & Yes & NA & Yes & 3 \\
Valley 2003 & Yes & NA & Yes & NA & Yes & 3 \\
Demirbilek 2004 & Yes & Yes & Yes & NA & Yes & 4 \\
Isik 2006 & Yes & Yes & NA & NA & Yes & 3 \\
Oh 2007 & Yes & Yes & NA & NA & Yes & 3 \\
Choi 2009 & Yes & NA & NA & NA & Yes & 2 \\
Locatelli 2013 & Yes & NA & NA & NA & Yes & 2 \\
Oofuvong 2013 & Yes & NA & NA & NA & Yes & 2 \\
Sethi 2013 & Yes & Yes & NA & NA & Yes & 3 \\
\hline
\end{tabular}


J Pharm Pharm Sci (www.cspsCanada.org) 18(2) 199 - 206, 2015

\begin{tabular}{|c|c|c|c|c|c|c|c|c|c|c|}
\hline \multirow{2}{*}{ Overall effects } & \multicolumn{2}{|c|}{ Sample size } & \multirow{2}{*}{ No. } & \multicolumn{2}{|c|}{ Test of association } & \multicolumn{2}{|c|}{ Test of heterogeneity } & \multirow{2}{*}{ Model } & \multicolumn{2}{|c|}{ Egger's test } \\
\hline & Desflurane & Sevoflurane & & WMD or RR $(95 \% \mathrm{CI})$ & $p$ & $p$ & $I^{2}(\%)$ & & $t$ & $p$ \\
\hline $\begin{array}{l}\text { Postoperative } \\
\text { Extubation time }\end{array}$ & 149 & 149 & 5 & $-3.87(-6.14 \text { to }-1.60)^{*}$ & $<0.01$ & $<0.01$ & 96.0 & Random & -12.4 & $<0.01$ \\
\hline Eye opening & 118 & 118 & 3 & $-1.11(-1.49 \text { to }-0.72)^{*}$ & $<0.01$ & 0.84 & 0.0 & Fixed & -0.16 & 0.9 \\
\hline Awakening time & 271 & 272 & 5 & $-4.27(-5.28 \text { to }-3.26)^{*}$ & $<0.01$ & 0.24 & 27.0 & Fixed & -4.1 & 0.03 \\
\hline $\begin{array}{l}\text { Discharge from the } \\
\text { Recovery room }\end{array}$ & 154 & 154 & 5 & $-0.91(-6.23,4.41)^{*}$ & 0.74 & 0.78 & 0.0 & Fixed & -0.14 & 0.9 \\
\hline $\begin{array}{l}\text { Oculocardiac } \\
\text { Reflex }\end{array}$ & 181 & 193 & 3 & $1.03(0.75 \text { to } 1.40)^{\#}$ & 0.87 & 0.69 & 0.0 & Fixed & -0.5 & 0.71 \\
\hline Agitation & 222 & 222 & 6 & $1.44(1.05 \text { to } 1.96)^{\#}$ & 0.02 & 0.38 & 5.0 & Fixed & 1.26 & 0.28 \\
\hline $\begin{array}{l}\text { Nausea and } \\
\text { Vomiting }\end{array}$ & 238 & 238 & 7 & $1.12(0.78 \text { to } 1.62)^{\#}$ & 0.54 & 0.49 & 0.0 & Fixed & 0.57 & 0.59 \\
\hline Severe pain & 110 & 110 & 3 & $0.95(0.68 \text { to } 1.33)^{\#}$ & 0.78 & 0.73 & 0.0 & Fixed & 0.53 & 0.69 \\
\hline
\end{tabular}

* weighted mean difference; \# represents risk ratio. CI, confidence interval; No., the number of comparisons; RR, risk ratio; WMD, weighted mean difference. 